SHORT REPORT

\title{
Dose and duration of hormone use: understanding the effects of combined menopausal hormones on breast cancer better, 1976-2004
}

\author{
Klim McPherson, Rebecca Mant
}

J Epidemiol Community Health 2005;59:1078-1079. doi: 10.1136/jech.2005.035147

$\mathrm{T}$ he effects of exogenous hormones on diseases that are hormonally related, particularly breast cancer, cause concerns. Breast cancer is common and the relation with hormones complex. Millions of women have taken menopausal oestrogen and progesterone (hormone therapy, HT) for prolonged periods to alleviate menopausal symptoms, to prevent osteoporosis, and to prevent coronary heart disease too.

The breast cancer risk of HT has been investigated since the 1970s in some 50 studies. ${ }^{1}$ It has been known that it was associated with an increase in breast cancer, but there has been confusion because of the possible differential effect of different hormones as well as of different durations, methods of application, and the effect of past use. It was none the less argued that the risk was small. ${ }^{2}$ It is surely a public health responsibility to clarify these risks as far as possible. This is particularly so when the marketing imperatives are so strong.

Use of combined therapy became common in the 1980s, after years of use of oestrogen alone were found to increase endometrial cancer risk, which the addition of progesterone eliminated. Thus epidemiological data on combined therapy were less mature and often confused with data on unopposed therapy, which had been the subject of most studies. The addition of progesterone could, in theory, have had a differential effect on breast cancer risk in any direction. ${ }^{3}$

The million women study, published in $2003,{ }^{4}$ showed that five years or more of use of combined HT doubles the risk among current users, which is more extreme than oestrogen alone. $^{5}$ Such a risk has important public health implications, when $25 \%$ of menopausal women were estimated to use HT by $2000{ }^{6}$ How much could we have known, by when, of the effect of long term combined HT use, with better pharmacovigilance? To investigate this question we have used quick and efficient statistical methods that require simple analyses of published data, and thus were available to all.

\section{METHODS}

We undertook a systematic review of the published research literature of all studies that examined the relative risk of breast cancer with five or more years of recent combined HT use. Some studies did not distinguish between unopposed or combined use and we included them only if the proportion of combined use was stated as being $30 \%$ or more. We pooled the risk estimates; using conventional fixed effect metaanalysis, ${ }^{7}$ calculated cumulative pooled estimates after each eligible study was published (final three columns in table 1). Where studies reported risk for several categories of use over five years we similarly pooled these estimates to provide one weighted estimate for each study. Relative statistical weights were estimated from the stated confidence limits of odds ratio (OR) estimates. Also where risks were only reported separately for subgroups, we pooled the estimated effects for the category closest to current use of five or more years of combined HT. ${ }^{8-18}$

\section{RESULTS}

It may be seen in table 1 that the million women study dominates any final estimates statistically as it was so large. It however estimates higher risks (significantly) than the synthesis of all other previous studies. Some small individual studies estimate risk higher than 2.0, but this is to be expected by chance. However by 1989 a pooled relative risk of around two was significant and hence should have been

Table 1 Cumulative synthesis of all studies examining the risk of breast cancer with more than five years use of combined HT, by publication year

\begin{tabular}{|c|c|c|c|c|c|c|c|c|c|}
\hline \multicolumn{4}{|c|}{ Cumulative meta-analysis } & \multirow[b]{2}{*}{ lower $\mathrm{Cl}$} & \multirow[b]{2}{*}{ upper $\mathrm{Cl}$} & \multirow[b]{2}{*}{ weight } & \multicolumn{3}{|c|}{ Cumulative pooled ORs } \\
\hline Study & Year & $\%$ Comb & (adj) OR & & & & OR & Lower $95 \% \mathrm{Cl}$ & Upper $95 \% \mathrm{Cl}$ \\
\hline Hunt & 1987 & 43 & 3.60 & 0.90 & 15.00 & 2 & 3.60 & 0.90 & 15.00 \\
\hline Ewertz & 1988 & 35 & 1.75 & 1.30 & 2.36 & 43 & 1.81 & 1.35 & 2.42 \\
\hline Bergkvist & 1989 & 100 & 4.40 & 0.90 & 22.40 & 2 & 1.86 & 1.40 & 2.47 \\
\hline Harris & 1992 & 39 & 1.20 & 0.65 & 2.23 & 10 & 1.72 & 1.33 & 2.23 \\
\hline Newcomb & 1995 & 100 & 1.12 & 0.72 & 1.76 & 20 & 1.54 & 1.23 & 1.93 \\
\hline Stanford & 1995 & 100 & 0.56 & 0.32 & 0.97 & 12 & 1.34 & 1.09 & 1.65 \\
\hline Magnussor & 1999 & 100 & 2.46 & 1.97 & 3.08 & 78 & 1.78 & 1.53 & 2.07 \\
\hline Shairer & 2000 & 100 & 1.74 & 1.22 & 2.48 & 30 & 1.77 & 1.54 & 2.04 \\
\hline Ross & 2000 & 100 & 1.63 & 1.43 & 1.85 & 224 & 1.70 & 1.54 & 1.87 \\
\hline Celbowsk WHI & 2003 & 100 & 1.97 & 1.36 & 2.85 & 28 & 1.71 & 1.56 & 1.88 \\
\hline \multirow[t]{2}{*}{$\mathrm{Li}$} & 2003 & 100 & 2.20 & 1.64 & 2.95 & 45 & 1.75 & 1.60 & 1.91 \\
\hline & & & & & total & 494 & & & \\
\hline Overview & 1997 & 100 & 1.53 & 0.88 & 2.18 & & & & \\
\hline Beral MWS & 2003 & $100 \%$ & 2.21 & 2.06 & 2.36 & 778 & & & \\
\hline
\end{tabular}


difficult to ignore. Publication bias may be in part responsible as the pooled estimate decreases during the 1990s, attributable to two studies with low risk estimates. Possibly this suggests the intrinsic unreliability of observational epidemiological study of a heterogeneous product, with changing use patterns. There is some heterogeneity between all these studies in both exposure and estimated effect, giving rise to opportunities for varied interpretations, but the net effect is unambiguous.

The large overview from the individual records from 51 studies published in 1997 shows a relative risk that is entirely consistent with this more simple synthesis of published results. There seemed to be little use of combined preparations in the collaborating studies, resulting in no significant effect of five or more years of combined HT use in 1997. The simpler analyses reported here show a significant effect well before that.

\section{CONCLUSIONS AND RECOMMENDATIONS}

The particular subgroup of exposure investigated was suggested partly from the results of recent studies. However, it does not seem excessive to suggest that any pharmaceutical product that has the potential for widespread use should be routinely investigated for possible serious long term side effects with respect both to essential composition (both constituent and dose) and duration of use. ${ }^{19}$ In this case the opportunity for systematically testing essentially two products (unopposed and combined HT) and two durations (less than five years and more than five years) for long term side effects from both randomised and observational studies was missed both by the public health community and regulators. But the ultimate responsibility rests with the manufacturers and their marketing departments-none the less independent assessment is essential. In this case the potential danger of long term use of combined HT on breast cancer risk could have been identified much earlier-but the pressure to accept any reliable notes of caution were powerfully resisted unless and until the evidence became entirely convincing, because of the real and perceived benefits of HT. In particular its putative cardioprotective effects were frequently cited-until shown to be illusory. ${ }^{20}$

In the UK around 15000 diagnoses of breast cancer are made each year among women aged 50-64. Acting on these results by using combined therapy sparingly strictly for symptoms, because of the increased breast cancer risk, might thus have saved around 2000 of these women from that disease per year. Clearly there is an issue with the downward trend in the early 1990s that would have been difficult to interpret without the benefit of hindsight. But since 1989 the pooled relative risk estimate was never non-significant, mostly highly significant and close to two.

\section{What this paper adds}

That simple analyses of existing studies should have led to a better understanding of attributable breast cancer risk of menopausal hormones-sooner

\section{Policy implications}

That such analyses should be routine in similar circumstances of common pharmaceuticals marketed with beneficial short term effect but unknown side effects.
The long term safety of medicinal products designed to alleviate common symptoms in the short term and that therefore have an enormous potential market require rigorous and routine assessment. Epidemiological studies should always report findings separately for drug type and categorised into meaningful duration groups. The paucity of epidemiological data in some groups early in the experience of a product is not a special problem when subjected to proper meta-analysis across studies as they accumulate. Indeed it is an essential part of such assessment. But it is necessary to be rigorous about sensible subgroups of exposure and outcome, a priori. This should be routine.

\author{
Authors' affiliations \\ K McPherson, R Mant, Nuffield Dept of Obstetrics and Gynaecology, \\ Oxford University, UK \\ Funding: none. \\ Conflicts of interest: none.
}

Correspondence to: Professor K McPherson, Oxford University, John Radcliffe Hospital Womens Centre, Level 3 Headington Oxford OX3 9DU, UK; klim.mcpherson@obs-gyn.ox.ac.uk

Accepted for publication 26 March 2005

\section{REFERENCES}

1 Collaborative Group on Hormonal Factors in Breast Cancer. Breast cancer and hormone replacement therapy: collaborative reanalysis of data from 51 epidemiological studies of 52705 women with breast cancer and 108411 women without breast cancer. Lancet 1997;350:1047-59.

2 ACOG committee opinion. Risk of breast cancer with estrogen+progetin replacement therapy. Int J Obs Gynecol 2002;76:333-5.

3 Stahlberg C, Pedersen AT, Lynge E, et al. Hormone replacement therapy and the risk of breast cancer: the role of progestins. Acta Obstet Gynaecol 2003:82:335-44.

4 Million Women Study Collaborators. Breast cancer and hormonereplacement therapy in the million women study. Lancet 2003;362:419-27.

5 The Women's Health Initiative Study Group. Effects of conjugated equine estrogen in post menopausal women with hysterectomy: the WHI randomised controlled trial. JAMA 2004;291:1701-12.

6 Townsend J. Hormone replacement therapy: assessment of present use, costs, and trends. Br J Gen Pract 1998;48:955-8.

7 Eggar M, Davey Smith G, Altman D. Systematic reviews in health care. London: BMJ Books, 2001.

8 Hunt K, Vessey M, McPherson K, et al. Long term surveillance of mortality and cancer incidence in women receiving hormone replacement therapy. Br J Obstet Gynaecol 1987;94:620-35.

9 Ewertz $M$, et al. Influence of non-contraceptive exogenous and endogenous sex hormones on breast cancer risk in Denmark. Int J Cancer 1988;42:832-8.

10 Bergkvist K, Adami HO, Persson I, et al. The risk of breast cancer after estrogen and estrogen-progestin replacement. N Engl J Med 1989;321:293-7.

11 Harris RE, Namboodiri KK, Wynder EL. Breast cancer risk: effects of estrogen replacement therapy and body mass. J Natl Cancer Inst 1992;84:1575-82.

12 Newcomb PA, Longnecker MP, Storer BE, et al. Long-term hormone replacement therapy and risk of breast cancer in postmenopausal women. Am J Epidemiol 1995; 142:788-95.

13 Stanford JL, Weiss NS, Voigt LF, et al. Combines estrogen and progestin hormone replacement therapy in relation to risk of breast cancer in middleaged women. JAMA 1995;274:137-42.

14 Magnusson C, Baron JA, Correia N, et al. Breast cancer risk following long term oestrogen and oestrogen-progestin replacement therapy. Int J Cancer 1999:81:339-44.

15 Schairer C, Lubin J, Troisi R, et al. Menopausal estrogen and estrogenprogestin replacement therapy and breast cancer. JAMA 2000;283:485-91.

16 Ross RK, Paganin-Hill A, Wan PC, et al. Effect of hormone replacement therapy on breast cancer risk. J Natl Cancer Inst 2000;92:328-32.

17 Chlebowski R, Hendrix S, Langer R, et al. Influence of estrogen plus progestins on breast cancer and mammography in healthy postmenopausal women. JAMA 2003;289:3243-53.

18 Li C, Malone K, Porter P, et al. Relationship between long durations and different regimens of hormone therapy and risk of breast cancer. JAMA 2003;289:3254-63.

19 Salpeter SJ, Walsh JME, Greyber E, et al. Mortality associated with hormone replacement therapy in younger and older women. J Gen Intern Med 2004; 19:791-804.

20 McPherson K, Hemminki E. Synthesising licensing data to assess drug safety. BMJ 2004;328:518-20. 